\title{
ENSINO DE DANÇA NA EDUCAÇÃ̃O INFANTIL: O CORPO E A LUDICIDADE NA CONSTRUÇÃO DO CONHECIMENTO
}

Carla Verônica Cesar Trigo ${ }^{\mathrm{i}}$

\begin{abstract}
Resumo: O presente trabalho desenvolve um estudo sobre o ensino da Dança na Educação Infantil. O objetivo dessa pesquisa é o de compreender o fenômeno do protagonismo infantil no ensino da Dança e suas implicações na prática pedagógica. Seu campo de intervenção é o Projeto “Dança Criança!", realizado no Centro de Referência em Educação Infantil do Colégio Pedro II. Os resultados evidenciam que, o projeto pedagógico em questão, propicia à criança tornar-se protagonista da sua aprendizagem. O método baseia-se em uma mediação que considera a criança como sujeito ativo no processo de construção do conhecimento e utiliza estratégias que privilegiam a experiência lúdica e a descoberta da corporeidade.
\end{abstract}

Palavras-chave: Dança; Educação Infantil; Protagonismo Infantil.

\section{DANCE EDUCATION IN CHILD EDUCATION: BODY AND PLAYFULNESSIN CONSTRUCTION OF KNOWLEDGE}

\begin{abstract}
This search develops a study on the teaching of dance in early childhood education. The intent of this research is to understand the phenomenon of child protagonism in the teaching of dance and its implications in the pedagogical practice. His field of intervention is the "Dance Child!" Project, held at the Pedro II High School Reference Center. The results show that the pedagogical project in question enables children to become protagonists of their learning. The method is based on a mediation it considers the child as an active subject in the process of knowledge construction and uses strategies, which privilege the ludic experience and the discovery of corporeality.
\end{abstract}

Keywords: Dance; Child Education; Child Protagonism.

\section{Introdução}

Segundo Goldenberg (1997), a escolha de um tema de estudo não surge espontaneamente, mas decorre de interesses e circunstâncias condicionados pela inserção do pesquisador na sociedade. Portanto, o olhar do pesquisador sobre o objeto está sempre vinculado a sua posição social e as correntes de pensamento do seu tempo.

Considerando a nova epistemologia da ciência e a evolução do paradigma emergente ${ }^{2}$, observa-se uma crescente produção acadêmica nos últimos anos a respeito da necessidade de superação de uma metodologia tradicional (BALDI, 2017), ainda existente no ensino da Dança para a primeira infância no contexto da Educação formal ${ }^{3}$. 


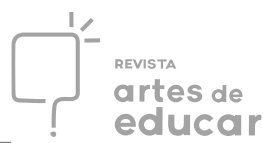

Tal metodologia baseia-se na lógica do professor-modelo/aluno-reprodutor, e é oriunda de um modelo hegemônico ${ }^{4}$ de ensino, pois, conforme afirma Baldi (2017, p. 293), se a Educação como um todo tem se pautado, na maior parte das vezes, a partir de uma perspectiva colonialista ${ }^{5}$, a Educação em Dança não é diferente.

Esse modelo se explicita tanto no modo como a Dança é ensinada em algumas escolas, quanto em seus conteúdos, que, muitas vezes, ainda privilegiam a estética clássica e seus saberes técnicos como representantes de uma dita cultura superior a ser alcançada, caracterizando o que Santos (2002 apud BALDI, 2017) denomina como "monocultura do saber".

Entretanto, para Freire (2005, apud PENNA, 2014), uma "Educação libertadora", ou seja, uma Educação que busca dar voz àqueles considerados ignorantes e inferiores, pressupõe o diálogo como fundamental ao processo pedagógico, por meio do qual o educando possa agir como sujeito questionador. Sendo assim, deve partir de temas que problematizem a realidade vivida e não da imposição de conteúdos prontos, alheios e alienantes.

Nesse ponto, é fundamental que se estabeleça os limites e as diferenças entre o ensino formal e não formal da Dança, compreendendo-se que, o primeiro, situa-se no contexto da Educação Básica e do Ensino Superior. Já o segundo, situa-se no contexto que está fora do âmbito escolar institucional, como as academias e escolas particulares de Dança, os projetos sociais, as associações comunitárias, as Igrejas e os espaços culturais (ALMEIDA, 2011).

Na Educação Básica, o ensino da Dança deve estar em consonância com o projeto político pedagógico das instituições escolares (Educação Infantil e Ensino Fundamental) com vistas ao desenvolvimento integral do aluno e, em Nível Médio/Técnico de forma articulada ou concomitante à formação profissional (BRASIL, 1996).

Vale ressaltar que, mesmo nos cursos profissionalizantes, entende-se que a formação deve ter início somente após os 6 anos, de modo que a criança não deixe de vivenciar as experiências essenciais ao seu desenvolvimento, podendo ser iniciada em uma determinada técnica, porém, ainda por meio de uma abordagem lúdica de ensino.

Com a necessidade de superação do modelo tradicional de ensino da Dança no contexto da Educação formal, chegamos ao seguinte problema: de que forma a criança pode desempenhar o papel de protagonista no processo de construção do conhecimento por meio da Dança? 


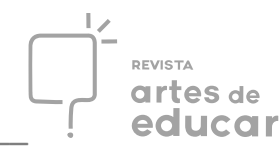

Este trabalho consiste em apresentar um recorte da pesquisa em desenvolvimento no Mestrado em Práticas da Educação Básica, do Colégio Pedro II, que tem como objetivo geral o fato de compreender de que forma a criança pode desempenhar o papel de protagonista no processo de construção do conhecimento por meio da Dança e quais as implicações desse "coprotagonismo" para a prática pedagógica, no que diz respeito ao papel desempenhado pelo professor.

Para atingir o objetivo proposto, adotamos uma abordagem qualitativa de pesquisa, do tipo fenomenológica, que de acordo com Gil (1946), caracteriza-se pela descrição da experiência vivida, buscando interpretar os fenômenos que se apresentam à percepção. Entretanto, considerando a forma de inserção no campo, o tipo de intervenção realizada e seu enfoque descritivo/interpretativo, podemos afirmar que esta pesquisa também tem características de uma pesquisa-ação, já que segundo Erickson (1986), o pesquisador interpretativo em ensino observa ativamente de dentro do ambiente estudado, imerso no fenômeno de interesse, registrando detalhadamente os eventos e que, para isso, ocupa-se de um grupo de indivíduos, tentando descobrir o que há de particular em determinada instância e o que pode ser generalizável em situações similares.

Pretende-se com essa pesquisa, contribuir para que o ensino de Dança na primeira infância possa ir além de uma prática na qual o professor é visto como modelo e a criança como mera reprodutora, mas que, ao invés disso, a criança possa desenvolver sua autonomia no processo de construção do conhecimento.

Para tanto, foi necessário tecer diversos "fios de conhecimento", tramando-se um “complexus", ou seja, promover um encontro entre as várias dimensões ou complexidades que envolvem o ensino da Dança para a Educação Infantil, a fim de desenvolver uma proposta pedagógica que busca privilegiar a linguagem corporal manifestada na Dança por meio da experiência e da descoberta da corporeidade.

\section{A fase do Personalismo}

Elaborar uma proposta de ensino da Dança voltada para a Educação Infantil demanda compreender o que caracteriza a fase de desenvolvimento da criança entre os 3 e os 6 anos de idade. Nesse sentido, encontramos, na teoria de Henri Wallon sobre a dinâmica do 


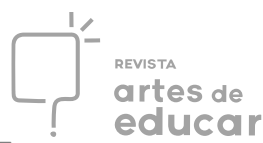

desenvolvimento infantil e a dialética afetividade/inteligência, o "fio" da Psicologia necessário para esta compreensão.

Segundo Wallon (1979 apud ALMEIDA e MAHONEY, 2009), a etapa dos 3 aos 6 anos é definida como a fase do "Personalismo". Essa fase se caracteriza como o período da "construção de si" em um ser diferente dos outros, um processo de discriminação eu-outro que culmina no fim do sincretismo anterior. A criança dessa idade, necessita se opor ao outro, expulsando-o de si, e ao mesmo tempo, imitá-lo para assimilá-lo e por fim, reelaborar sua própria personalidade.

De acordo com Grandino (2010), nesse estádio, há predomínio da afetividade e é quando se formam a personalidade e a autoconsciência, o que pode se refletir em oposições da criança em relação ao adulto e, ao mesmo tempo, em imitações motoras e de posturas sociais.

Entretanto, o estudo de Wallon (1979) demonstra que, dada a sua complexidade, não existe uma sucessão linear das fases ou etapas de desenvolvimento da criança. Assim, mesmo que demarcadas, as crises, as sobreposições e as contradições dessas fases alternam-se e, ao contrário do que muitas vezes se pensa, são benéficas e dinamizadoras do processo.

A crise da oposição se caracteriza pela expulsão do que há de alheio de dentro de si. Pela interação, ocorre a negação do outro e, instrumentalizada pela linguagem e pela função simbólica, a percepção de si se transforma na "consciência de si", que exige espaço para todo o tipo de manifestação expressiva e para diferentes formas de linguagem (DANTAS, 1992).

Na idade da graça, a criança precisa da admiração alheia para completar a construção do seu Eu e, por isso, faz questão de mostrar suas descobertas. Tais características tornam essa fase, um momento oportuno para que a criança seja estimulada a explorar sua corporeidade, a criar e a compartilhar suas experiências com o outro. Portanto, o professor deve demonstrar à criança que está atento ao seu processo e que valoriza o que é construído por ela, incentivando o seu prazer pela descoberta e pela criação.

Na fase da imitação, é a admiração pelo outro como modelo que levará a criança à ampliação das suas competências (idem), pois o prestígio atribuído pela criança a um determinado modelo gera nela uma necessidade de aproximação e de semelhança.

Assim, é a própria criança quem elege seus modelos, reproduzindo aqueles que captam o seu interesse (WALLON, 2008).

Esse pesquisador (idem) explica que, quando há um período de incubação, a imitação se aproxima da representação, realizando-se como resultado e integração das suas experiências 


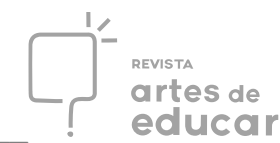

e impressões. A imagem, então, consiste em fundir um conteúdo múltiplo de impressões captadas pelas suas experiências em uma unidade e, com isso, o movimento passa de eficiente a simbólico (ibidem).

\section{Da imitação à expressão}

O modelo tradicional de ensino da Dança para crianças, que ainda se perpetua em coexistência com as novas propostas que vêm surgindo com o movimento da Dança-Educação, baseia-se em referenciais "eurocêntricos" e na crença de que o professor detém todo o saber (FREIRE, 2005 apud PENNA, 2014). Com uma visão equivocada sobre a criança na primeira infância, suas estratégias, tanto em contextos não formais, quanto nos contextos formais de Educação, muitas vezes se limitam a aprendizagem de gestos representativos de letras de músicas que devem ser reproduzidos e memorizados ou, então, a aprendizagem e a repetição mecânica do repertório de movimentos do Ballet de maneira precoce. Todavia, de acordo com as Diretrizes Curriculares Nacionais para a Educação Infantil, o papel dos educadores nesse segmento não representa uma [...] condução absoluta de todas as atividades e centralização das mesmas em sua pessoa (BRASIL, 2013, p.14).

Baldi (2017) corrobora essa ideia quando expõe as características presentes nesse tipo de ensino que estamos chamando de tradicional, como: a dissociação entre o ensinar e o aprender; a verticalidade das relações; a codificação do movimento; a valorização do produto e não do processo, e o professor como autoridade e única fonte de conhecimento. Por outro lado, Stokoe (1987, p. 22) afirma que a repetição pode ser uma forma de aprofundar e enriquecer um aprendizado quanto a novas possibilidades de utilização do corpo e que desde que a criança não perca sua motivação, ela poderá, quantas vezes desejar, voltar ao mesmo tema.

O que devemos ter em mente sobre essa questão é que o problema não está no fato de se utilizar a imitação e a repetição do movimento como estratégias de aprendizagem, mas na forma e no objetivo para que estas estratégias são utilizadas, seja repetindo o movimento com a finalidade de aperfeiçoá-lo tecnicamente ou padronizando o movimento dentro de um determinado estilo, excluindo, dessa forma, todas as outras possibilidades a serem exploradas pela criança.

Esta constatação remete-nos ao pensamento de Laban (1990, p. 2), quando esse autor afirma que em uma técnica de dança livre, isto é, sem estilo preconcebido [...] vive-se a gama 


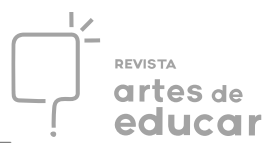

total do movimento e que é nessa universalidade das formas de movimento que reside o valor educacional da 'nova técnica'

Sobre a questão da repetição, afirma (idem) que ela é natural e que tem valor, desde que parta de um "impulso de mover-se", ou seja, do ímpeto para o movimento, característico dessa fase, por meio do qual a criança libera sua energia expressiva.

O impulso espontâneo de mover-se seria, também, um escape que a Dança oferece para a sensação de mal-estar provocada pela repressão dos movimentos do corpo, uma vez que as crianças, quando entram no 'terreno sagrado da escola', [...] sofrem uma espécie de apartheid de seu ethos lúdico ${ }^{8}$ (GOMES, 2009, p. 115, grifos do autor), que faz com que o aprender a controlar tais impulsos do próprio corpo seja considerado uma virtude da criança, transformando esse "controle do corpo" numa atitude valorizada e estimulada pela escola.

Nesse sentido, o impulso de dançar diminui proporcionalmente ao aumento da idade, e podemos afirmar, ao longo do processo de escolarização, fazendo com que a criança, ao adquirir, às vezes forçadamente, o ideal da relativa imobilidade do adulto (LABAN, 1990, p. 25) perca o seu impulso de dançar.

Esse autor (idem) explica que os movimentos da criança que não têm um objetivo específico, isto é, que têm como único fim o desejo instintivo de desenvolver seus esforços, ficam em segundo plano tornando-se cada vez mais conscientemente controlados.

Ainda segundo esse autor (ibidem), com a conquista da sustentação do corpo e do caminhar, a criança escolhe e repete certas ações rítmicas pelo simples prazer do movimento, pois a repetição de séries de esforços simultâneos, equilibrados entre si, traz à criança um prazer estético, também chamado de 'fruição estética'. Com isso, podemos entender que a repetição deve partir da necessidade da criança em retornar a um determinado tema de experiência e que, reafirmando o que ressalta Almeida (2017), é necessário que se dê mais espaço e tempo para as experimentações sobre o que ela própria identifica como atividade de fruição estética, e que, além disso, o educador seja capaz de perceber o potencial das atividades eleitas pela criança para a construção de novos saberes.

O prazer estético, presente na Dança e manifestado no gosto pela repetição do movimento, indica que a repetição de temas do interesse da criança pode ser uma estratégia para estimulá-la a novas descobertas. Entretanto, isto irá depender diretamente da escuta e do conhecimento do professor, ou seja, da sua capacidade de interpretar a fala do corpo e de estimular a criança à descoberta sobre o seu corpo e suas relações com o mundo 9 . 


\section{O lúdico na Dança}

Chateau (1987 apud BARBOSA; GOMES, 2010) ressalta a importância da atividade lúdica no comportamento e na natureza infantil e seu papel no estímulo à autoafirmação e à construção da personalidade, ressaltando a relação da criança com o objeto lúdico.

O jogo para a criança é coisa séria, e por isso, represa toda a sua atenção. Quando brinca, é como se o jogo operasse um corte no mundo, destacando do ambiente o objeto lúdico para apagar todo o resto (BARBOSA; GOMES, 2010, p.21). Dessa forma, a brincadeira passa a ser um mundo à parte, próprio da criança, pelo qual ela tem o poder de se distanciar da realidade concreta do mundo adulto, realizar sua imaginação, suas vontades e assim afirmar sua personalidade.

Essa característica de trabalho e de atividade mobilizadora da atenção da criança para o objeto evidencia a importância da ludicidade como estratégia a ser utilizada no processo de construção do conhecimento, especialmente, quando nos empenhamos na busca por metodologias abertas e não tradicionais.

Segundo Barbosa e Gomes (2010), a conduta lúdica ${ }^{10}$ da criança cria uma atmosfera de imaginação, permitindo que ela veja além do significado real do objeto, transformando-o e dando-lhe um novo sentido. Permite também que a criança possa escapar da realidade e retornar a ela quando deseja, ou quando, pela sua percepção sobre o ambiente, julga necessário (idem).

Por meio desse domínio sobre a evasão consciente da vida real, próprio da criança, as leis e os costumes do quotidiano perdem a validade (HUIZINGA,1999). Sendo assim, ao brincar, ela se transporta temporariamente para um mundo de fantasia, de um fazer extraordinário no qual ela realmente acredita e onde tem o poder de recriar a realidade.

Esse autor (idem) considera a Dança desde a Pré-história e da Antiguidade, em todos os povos, a mais pura e perfeita forma lúdica de jogo. Com essa definição sobre a função do jogo, ressalta (ibidem, p. 17) que podemos classificar a ludicidade na Dança dentro do aspecto da representação, na qual

[...] a criança fica literalmente 'transportada' de prazer, superando-se a si mesma a tal ponto que quase chega a acreditar que realmente é esta ou aquela coisa, sem, contudo, perder inteiramente o sentido da "realidade habitual". Mais do que uma realidade falsa, sua representação [...] é imaginação, no sentido original do termo. (grifo do autor) 
O sentido do termo imaginação a que se refere esse renomado pesquisador é o da fantasia, da faculdade criadora, do devaneio realizado pela criança em forma de brincadeira.

\section{A abordagem de Reggio Emília no ensino da Dança}

Tramando esse "complexus" a respeito do ensino da Dança para a Educação Infantil, vimos a necessidade de incluir nele o "fio" do campo da Pedagogia.

Com o que Rinaldi (2016) denomina como "Pedagogia da relação e da escuta", buscamos compreender o fenômeno do protagonismo infantil e como pode acontecer no ensino da Dança para crianças. Para isso, escolhemos por referência, a Abordagem Pedagógica de Reggio Emília, uma das bases que fundamenta o projeto político-pedagógico do CREIR ${ }^{11}$.

Segundo Guanais (2017), a Abordagem Pedagógica de Reggio Emilia foi criada por Loris Malaguzzi nos anos 1950/1960 e baseia-se nos estudos de Piaget, Vigotsky e Dewey, além de ter influências de pedagogos italianos, como Maria Montessori, irmãs Agazzi, Bruno Ciari e do movimento ativista da Educação daquela época. Ela se constitui na abordagem pedagógica adotada pelas creches municipais dessa cidade, situada no norte da Itália, após a Segunda Guerra Mundial.

Um dos fundamentos dessa abordagem é a experiência significativa, que tem por objetivo formar futuros cidadãos críticos com diferentes visões acerca do mundo. Malaguzzi (1999) parte do pressuposto de que a criança nasce com 'cem linguagens' e, por isso, tem como prioridade a escuta e o reconhecimento das múltiplas potencialidades da criança, que devem ser observadas e atendidas em sua individualidade. Para tanto, além de valorizar a experiência individual, o conhecimento é tratado de forma interdisciplinar, o que evidencia o trabalho em prol do desenvolvimento de várias habilidades e competências da criança (GUANAIS, 2017, grifo do autor).

Propomos, então, identificar as ações dessa abordagem que irão compor a tessitura do projeto aqui proposto. Porém, vale ressaltar que, tratando-se de realidades tão distintas, devemos retomar o pensamento de Freire (2005), no sentido da busca de uma Educação Libertadora, de modo a considerar a realidade na qual o aluno está inserto e, com isso, não recair no "mito do eurocentrismo" 12 . Assim, é necessário que o professor reflita a respeito das 


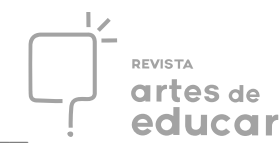

adaptações necessárias, considerando questões como a infraestrutura, os recursos materiais, a quantidade de alunos por turma e a localidade da escola.

\section{Ações da abordagem de Reggio Emília no ensino da Dança:}

A escuta se constitui em uma das principais ações da abordagem Reggio Emília. Sendo assim, segundo Sá (2010, p. 63), todas as decisões pedagógicas estão atreladas à interpretação do educador sobre o que a criança deseja, o que ela faz, o que ela consegue produzir, suas possibilidades, suas teorias.

De acordo com essa autora (idem, p. 62), nessa abordagem, a relação ensinoaprendizagem não tem um sentido único, já que se propõe a uma escuta recíproca e nesse sentido, o valor atribuído ao diálogo e a atenção a ela dirigida não são improviso, pois, para esses educadores, as competências da criança se desenvolvem e são ativadas pela experiência na qualidade da interação.

Segundo Rinaldi (2016), a escuta ocorre dentro de um contexto em que se aprende a ouvir, um contexto de "múltipla escuta", que é diferente da relação tradicional de "ensinoaprendizagem". Nesse sentido, a múltipla escuta envolve a escuta de si mesmo ${ }^{13}$, das outras crianças e do educador.

Dentro desse contexto, a criança se sente legitimada para oferecer suas teorias, pois o valor do ponto de vista e da interpretação de todos sobre as questões que se põem é reconhecido pelo grupo. Sendo assim, a escuta, segundo Rinaldi (2016):

- É gerada por curiosidade, desejo, dúvida e incerteza;

- Produz perguntas e não respostas;

- Envolve dar uma interpretação à mensagem e valorizar aqueles que são escutados;

- Exige a suspensão dos nossos julgamentos e preconceitos;

- Exige abertura à mudança e ao questionamento das nossas certezas.

Podemos perceber com as afirmativas dessa pesquisadora que, nesse tipo de abordagem pedagógica, o educador deve sair do lugar de detentor único do conhecimento e colocar-se, junto com a criança, no lugar de educando, predispondo-se a estar aberto à incerteza e ao inesperado, aprendendo junto com ela, numa relação de horizontalidade.

Com essa metáfora das cem linguagens de Malaguzzi, estaremos considerando, neste trabalho, a escuta do corpo como o aspecto principal no ensino da Dança para crianças, pois 
uma prática que se propõe a considerar a criança como protagonista de sua aprendizagem pressupõe que o professor esteja predisposto a ouvir e, além disso, que ele esteja preparado para interpretar a fala desse corpo infantil. Dessa forma, estaremos entendendo aqui o corpo como uma das cem linguagens da criança manifestada na Dança.

O segundo aspecto a ser considerado nessa abordagem é a questão da imagem que se têm da criança, pois é esta imagem que o educador faz da criança que irá orientar sua postura, seus procedimentos e sua compreensão a respeito do papel que irá desempenhar.

Se o professor acredita que detém o conhecimento e a criança apenas recebe o que ele sabe, a organização do trabalho pedagógico estará presa a estratégias tradicionais, baseadas no modelo e na repetição de movimentos. Porém, se ao invés disso, a criança para o professor representa um ser potente, que toma decisões, atento à sua atualidade e que constrói seu conhecimento, a proposta pedagógica terá necessariamente que superar os modelos tradicionais.

Com essa imagem da criança, segundo Sá (2010), o professor torna-se um estimulador, que alimenta suas ideias, cria parcerias, encoraja a realização de novos experimentos e orienta o desenvolvimento de projetos que partem da sua curiosidade e do seu interesse.

Outro aspecto que se destaca nessa abordagem (principalmente quando falamos da experiência na Dança e em qualquer outra linguagem da Arte) é o aspecto do ambiente ou da ambientação. Visto como conteúdo educacional, o ambiente veicula mensagens e é determinante para o estímulo à descoberta. Sendo assim, passa a ser mais uma questão que dependerá do papel de "coconstrutor" 14 do conhecimento a ser mobilizado pelo professor e das suas escolhas em relação à criação desse cenário, que, pensado e planejado para propiciar a experiência, se torna potencialmente propiciador da liberdade expressiva da criança.

Segundo Rinaldi (2016), o registro e a documentação (quarto aspecto a ser considerado) devem acontecer durante o processo e não no seu final, fazendo parte da vida cotidiana. Tratase de tornar visível, por meio de instrumentos como vídeos, gravações, slides, fotografias e outros, o "como" os indivíduos estão se desenvolvendo dentro do processo coletivo de construção do conhecimento. Desse modo, a documentação está interligada à observação, interpretação e avaliação, possibilitando à criança, que também se torna observadora, reconhecer-se dentro do processo e, desse modo, adquirir consciência da sua aprendizagem.

É importante ressaltar que todo registro é imbuído com a subjetividade do "professordocumentarista-pesquisador", que, ao escolher, registrar e compartilhar uma determinada 


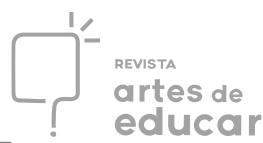

experiência dentro do contexto geral de aprendizagem, está avaliando ou valorizando ${ }^{15}$ esta experiência como significativa, tanto para a criança quanto para sua própria aprendizagem. Com isso, segundo Rinaldi (2016), a criança sente que, dentro da construção coletiva, a sua contribuição individual tem valor e que o professor aprende junto com ela.

\section{As experiências da Dança na Educação Infantil e o papel do "Dança-educador"}

Damásio (2000) compreende a faixa etária entre 4 e 6 anos como a fase do "despertar" do corpo. Nela, o professor deve favorecer, por meio do estímulo, descobertas sobre o peso, o equilíbrio e os contrastes na relação do corpo com o espaço e o tempo (baixo/alto, lento/rápido, grande/pequeno), de modo a valorizar as criações da criança. Ele deve estimular a descoberta de diferentes partes do corpo, fazendo com que a criança perceba as articulações e o espaço em torno dele, desenvolvendo a percepção do seu volume. Pode propor também, jogos com objetos e com os outros, no intuito de propiciar a experimentação de qualidades distintas do corpo. $\mathrm{O}$ professor deve utilizar verbos de ação capazes de suscitar, provocar a experimentação de qualidades distintas nos movimentos das crianças.

Laban (1990) acredita que, até os 4 anos, as experiências na Dança devem acontecer por meio de estímulos e que a criança deve apenas reagir a esses estímulos e não imitar, empregando suas próprias ideias e esforços. Entende (idem), também, que o professor não deve corrigir os movimentos e nem tentar ajustá-los a normas. Não deve exigir precisão ou concentração e nem impor formações espaciais (ibidem).

Ainda segundo esse autor (ibidem), já entre 5 e 7 anos, a criança se torna mais capaz de expressar-se e é possível observar movimentos característicos da sua personalidade. O professor pode enfocar uma parte do corpo por vez, porém, a criança ainda precisa usar seu corpo todo como modo de expressão, incluindo um grande número de articulações e não estar tecnicamente interessada em uma parte, já que a ação de uma só articulação produz uma repressão do restante da atividade corporal, do impulso de mover-se, trazendo um desassossego ao corpo (ibidem).

Os "fatores de movimento" (tempo, espaço, peso e fluência), componentes que foram identificados por esse autor ao observar as atitudes corporais do cotidiano, também são elementos de experiência essenciais a serem abordados no ensino da Dança na primeira infância e de acordo com Rengel (2001, p. 14), “[...] estão no agente naturalmente presentes. No 


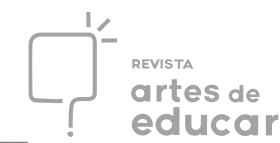

entanto, é preciso uma atitude interna ativa [...]”. Com essa atitude, é gerado o modo de o movimento ocorrer (idem). Assim, o professor pode estimular a criança a experimentar as diferentes atitudes internas da ação (movimento intencional) dentro de um determinado tema.

Ao analisarmos os estudos de Laban, podemos perceber que se fala em elementos como fatores e temas de movimento e não em exercícios ou passos, o que nos leva a crer que a prática pedagógica da Dança no contexto escolar deve ter um caráter de mediação e de estímulo à experiência e não de condução ou direção total das atividades. É essa característica de mediador que diferencia o professor tradicional de Dança do que estamos chamando de um Dançaeducador.

\section{“Dança Criança!": o protagonismo infantil em ação}

As experiências relatadas aqui fizeram parte da proposta de intervenção realizada com os alunos do "Dança Criança!"16, em 2019, que se constituiu em uma das etapas da pesquisa em andamento.

O estudo de Laban sobre o valor educacional da Dança nos diferentes grupos de idade representa um dos "fios" que se entrelaçam para compor a proposta pedagógica do projeto "Dança Criança!", determinando grande parte das suas experiências ou conteúdos.

Nesse estudo, Laban (1990) elenca 16 "temas básicos de movimentos", nos quais estão contidos 8 "temas elementares", apropriados segundo o autor, ao ensino de Dança para crianças até os 11 anos. Entre esses, elegemos dois temas para aprofundar neste artigo: "A consciência do corpo" e "A consciência do espaço", que serão bordados nos relatos a seguir.

Relato 1 - Tema básico de movimento: "A consciência do corpo"

Este tema, como o próprio nome sugere, é desenvolvido por Laban (1990) com o objetivo de conscientizar a criança sobre as possibilidades de uso das partes do corpo.

Demonstrando o seu entendimento sobre a importância da ludicidade no ensino da Dança para crianças, esse autor busca dar exemplos concretos sobre como abordar tais temas, ressaltando que esta abordagem deve acontecer por meio das brincadeiras, nas quais o próprio corpo e suas partes podem representar o objeto lúdico.

Almeida (2011) determina a "noção corporal" como um princípio da Dança para a Educação Infantil. Com base em Fonseca (1995; 2008), há a explicação de que a noção corporal 


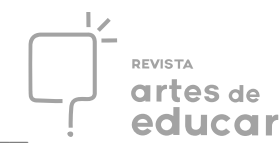

une dois conceitos (o esquema e a imagem-corporal) e que ambos os conceitos influenciam e somam-se um ao outro.

O esquema corporal envolve o conhecimento e a consciência do próprio corpo e de suas partes em relação ao meio envolvente, desenvolvendo-se por meio das experiências de movimento e das sensibilidades corporais internas e externas, principalmente, das impressões posturais, originárias das articulações e dos músculos, chamada propriocepção (WALLON, 1975 apud ALMEIDA, 2011).

Nesse sentido, as vivências do esquema corporal através da estimulação ao conhecimento da estrutura e à consciência do corpo podem proporcionar a apropriação e a atualização da imagem corporal pela representação mental do corpo (ALMEIDA, 2011).

Com esse escopo teórico da pesquisa, propôs-se o tema de experiência "corpo brinquedo". Este tema surge da ideia de utilizar o objeto lúdico como estratégia para estimular a experiência e as descobertas sobre o esquema corporal.

Os desdobramentos decorrentes da prática da escuta, no decorrer do processo de desenvolvimento do tema nas aulas, tornaram possível englobar nessas experiências a compreensão sobre a relação parte/todo do corpo e também a apropriação da imagem corporal pela criança.

A seguir, apresentamos um quadro esquemático elaborado como pré-teste para a coleta de dados, que ilustra de forma resumida a proposta inicial do tema e o que foi observado ao longo do seu desenvolvimento. Também compõem este quadro algumas unidades de contexto e de registro inferidas nesta primeira fase da pesquisa, determinadas com base no escopo do trabalho e nas técnicas da Análise de Conteúdo (BARDIN, 2016), além dos desafios enfrentados para o desenvolvimento do tema. 
Quadro 1 - Instrumento de coleta de dados / tema: "Corpo brinquedo"

\begin{tabular}{|c|c|c|}
\hline \multicolumn{3}{|c|}{$\begin{array}{l}\text { PROJETO "DANÇA CRIANÇA!" } \\
\text { QUADRO DE OBSERVAÇÃ̃O }\end{array}$} \\
\hline \multicolumn{3}{|c|}{ Tema de experiência: "Corpo brinquedo" } \\
\hline \multicolumn{3}{|c|}{ Proposta inicial } \\
\hline $\begin{array}{l}\text { Objetivos: } \\
\text { - } \\
\text { Desenvolver a noção de } \\
\text { esquema corporal; } \\
\text { - Estimular a produção } \\
\text { coletiva; } \\
\text { - Apropriar-se } \\
\text { imagem corporal. da }\end{array}$ & $\begin{array}{l}\text { Estratégias: } \\
\text { - Identificar as partes do corpo; } \\
\text { - Montar coletivamente, um } \\
\text { "corpo brinquedo" com os } \\
\text { materiais reciclados; } \\
\text { - Observar as formas e os } \\
\text { tamanhos das partes. }\end{array}$ & $\begin{array}{l}\text { Recursos/ambientação: } \\
\text { Materiais reciclados (rolos } \\
\text { de guardanapo, rolos de } \\
\text { papel higiênico, tampas de } \\
\text { garrafas, tampas de lata de } \\
\text { leite, tampas de pote de } \\
\text { requeijão). }\end{array}$ \\
\hline \multicolumn{3}{|c|}{ Ações de protagonismo das crianças } \\
\hline $\begin{array}{l}\text { Experimentações e } \\
\text { descobertas: }\end{array}$ & \multicolumn{2}{|c|}{$\begin{array}{l}\text { - Montagem individual do quebra-cabeças; } \\
\text { - } \quad \text { Manipulação do boneco; } \\
\text { rosto, idade, nome, roupa). }\end{array}$} \\
\hline Diálogos & \multicolumn{2}{|c|}{$\begin{array}{l}\text { - } \text { Professora: "-O que está faltando no boneco?" } \\
\text { - Criança: "- Está faltando a roupa dele, ele não pode ficar } \\
\text { pelado..." } \\
\text { - } \\
\text { - Crofessora: “- Todos os corpos são iguais?" "- Algumas pessoas não têm uma parte do corpo..." }\end{array}$} \\
\hline \multicolumn{2}{|c|}{ Desdobramentos do tema: } & Recursos/ambientação: \\
\hline \multicolumn{2}{|c|}{$\begin{array}{l}\text { - Problematização sobre a questão da diversidade de corpos; } \\
\text { - } \quad \text { Montagem de um boneco articulado; } \\
\text { - } \text { Observação das articulações do corpo; } \\
\text { - } \quad \text { Desenho o rosto do boneco; } \\
\text { - } \text { Confecção da roupa do boneco; } \\
\text { - } \quad \text { Panipulação do boneco pelas crianças; } \\
\text { - } \text { fazer parte da turma); } \\
\text { - } \text { bxperimentação das possibilidades de movimento do corpo (o } \\
\text { - Exploração da relação corpo e espaço geral; } \\
\text { - Comparação entre o tamanho do boneco e o tamanho das } \\
\text { crianças. }\end{array}$} & $\begin{array}{ll}\text { - } & \text { Barbante; } \\
\text { - } & \text { Tesoura; } \\
\text { - } & \text { Palitos de picolé; } \\
\text { - } & \text { Fita durex colorida; } \\
\text { - } & \text { Papel colorido; } \\
\text { - } & \text { Marcador permanente. }\end{array}$ \\
\hline \multicolumn{2}{|c|}{ Desafios: } & Estratégias de superação: \\
\hline \multicolumn{2}{|c|}{$\begin{array}{l}\text { - Montagem do boneco de forma coletiva, uma vez que a criança, } \\
\text { nessa fase, ainda está desenvolvendo o senso de coletividade e } \\
\text { aprendendo a compartilhar; } \\
\text { Mobilizar a comunidade escolar para a arrecadação de materiais } \\
\text { recicláveis. }\end{array}$} & $\begin{array}{l}\text { - Estímulo à valorização } \\
\text { da produção coletiva; } \\
\text { Envolvimento da } \\
\text { comunidade escolar no } \\
\text { projeto por meio de } \\
\text { encontros abertos. }\end{array}$ \\
\hline
\end{tabular}

Fonte: a autora, 2019 

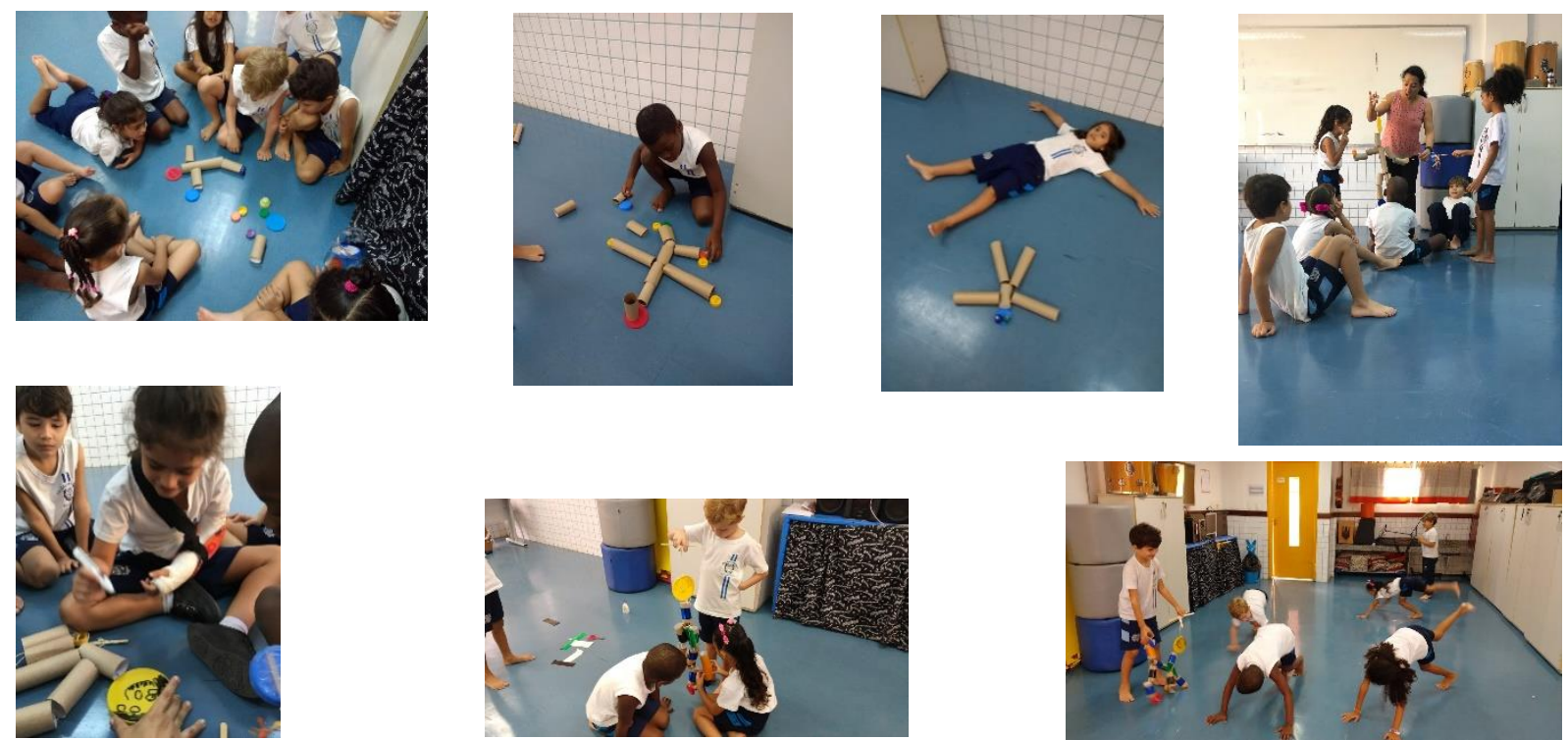

Relato 2 - Tema básico de movimento: "A consciência do espaço"

Antes de adotar qualquer sistema de ensino nas escolas, é conveniente compreender os esforços instintivos da criança para seu autodesenvolvimento [...] A primeira atividade do bebê consiste em mover seus membros. Ao afastar as pernas do centro do seu corpo e golpear com os braços, vai diminuindo a posição esférica [...] que o corpo adota no estado embrionário (LABAN, 1990, p. 21).

Segundo Laban (1990) a iniciação a uma Dança-educativa para crianças deve partir dos movimentos instintivos do bebê. Esses movimentos são sempre bilaterais e repetem-se ritmicamente.

No tema "A consciência do espaço", esse autor (idem) considera a importância de conscientizar a criança sobre a diferença entre os movimentos amplos e restritos, divergentes ou convergentes em relação ao seu corpo. Essas ações de recolhimento e expansão do corpo remetem à diminuição da posição esférica do feto para a expansão do corpo até o limite de alcance dos membros (ibidem). 


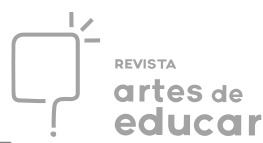

Os movimentos do bebê acontecem dentro da "Kinesfera" ou "cnesfera" ou do espaço pessoal, um dos principais conceitos desenvolvidos por Laban, proveniente do seu estudo sobre a Corêutica ${ }^{17}$.

Segundo Rengel (2001), a Kinesfera é a esfera pessoal de movimento que determina o limite natural do espaço pessoal. Essa esfera de espaço cerca o corpo, esteja ele em movimento ou em imobilidade e é delimitada pelo alcance dos membros e outras partes do corpo quando se esticam para longe do seu centro. Para fora desta esfera imaginária imediata, está o espaço mais amplo, o geral. Assim, nunca saímos de nossa esfera pessoal, pois ela é levada conosco, acompanha-nos pelo espaço (LABAN, 1990, p. 23)

A percepção/conscientização sobre o espaço pessoal - e deste dentro do espaço geral é considerada neste trabalho como experiência essencial na iniciação à Dança para crianças. Assim, estabelecendo uma relação entre o conceito de "Kinesfera" e a importância dos movimentos de expansão e recolhimento do corpo na iniciação à Dança com crianças surgiu o tema de experiência "O bebê", relatado no quadro a seguir.

Com os desdobramentos desse tema, foi possível realizar apreciações estéticas das experiências de movimento resultantes da relação entre o corpo e o objeto, registradas por meio de fotografias ao longo do processo.

Quadro 2 - Instrumento de coleta de dados/tema "O bebê"

\begin{tabular}{|c|c|c|}
\hline \multicolumn{3}{|c|}{$\begin{array}{c}\text { PROJETO "DANÇA CRIANÇA!" } \\
\text { QUADRO ESQUEMÁTICO DE OBSERVAÇÃO }\end{array}$} \\
\hline \multicolumn{3}{|c|}{ Tema de experiência: "O bebê" } \\
\hline \multicolumn{3}{|c|}{ Proposta inicial } \\
\hline $\begin{array}{l}\text { Objetivos: } \\
\text { - Explorar os movimentos } \\
\text { de expansão e o } \\
\text { recolhimento do corpo; } \\
\text { - Perceber o alcance dos } \\
\text { membros no espaço } \\
\text { pessoal; } \\
\text { Explorar as diferentes } \\
\text { bases de apoio e } \\
\text { locomoções pelo espaço } \\
\text { geral. }\end{array}$ & $\begin{array}{l}\text { Estratégias: } \\
\text { - De olhos fechados, fingir que } \\
\text { voltou a ser bebê e está dentro da } \\
\text { barriga da mãe, assumindo a } \\
\text { forma esférica do corpo; } \\
\text { - Expandir e recolher as partes do } \\
\text { corpo; } \\
\text { - Movimentos instintivos do bebê } \\
\text { (chutar, socar); } \\
\text { - Rolar de um lado para o outro até } \\
\text { chegar em decúbito ventral; } \\
\text { - Explorar o espaço ao seu redor } \\
\text { através do olhar e dos } \\
\text { movimentos da coluna cervical; }\end{array}$ & $\begin{array}{l}\text { Recursos/ambientação: } \\
\text { - Penumbra } \\
\text { - Música }\end{array}$ \\
\hline
\end{tabular}




\begin{tabular}{|c|c|c|}
\hline & $\begin{array}{l}\text { - Progressão locomotora: arrastar- } \\
\text { se pelo espaço - engatinhar - } \\
\text { quadrupedar, caminhar, correr. }\end{array}$ & \\
\hline \multicolumn{3}{|c|}{ Ações de protagonismo das crianças } \\
\hline $\begin{array}{l}\text { Experimentações e } \\
\text { descobertas: }\end{array}$ & \multicolumn{2}{|c|}{$\begin{array}{l}\text { - Emitir os balbucios característicos do bebê; } \\
\text { - Interagir com os outros "bebês"; } \\
\text { - Dois bebês gêmeos na barriga da mesma mãe; } \\
\text { - Andar desequilibrando-se e caindo. }\end{array}$} \\
\hline Diálogos: & \multicolumn{2}{|c|}{$\begin{array}{l}\text { Professora: "- Não é só para imitar um bebê, mas para lembrar os seus } \\
\text { movimentos..." "Tentem lembrar de como era estar dentro da barriga } \\
\text { da mãe." } \\
\text { Criança: "- Era escurinho." } \\
\text { Criança: "- Estou vendo dentro da barriga da minha mãe." } \\
\text { Professora: "- É um bebê em cada barriga." } \\
\text { Criança: "- Mas nós somos gêmeos! " }\end{array}$} \\
\hline \multicolumn{2}{|c|}{ Desdobramentos do tema: } & Recursos/ambientação: \\
\hline \multicolumn{2}{|c|}{$\begin{array}{l}\text { - Utilizar tecidos para simular o espaço delimitado pelo útero materno; } \\
\text { - Sentir a "elasticidade" do espaço delimitado pelo tecido (útero) pelos } \\
\text { movimentos de recolhimento e expansão dos membros; } \\
\text { - Observar o efeito estético das formas criadas registrados em } \\
\text { fotografias. }\end{array}$} & $\begin{array}{l}\text { - Cortes de tecido de } \\
\text { diversas cores; } \\
\text { - Som do útero } \\
\text { materno; } \\
\text { - Aparelho de TV. }\end{array}$ \\
\hline \multicolumn{2}{|r|}{ Desafios: } & Estratégias de superação: \\
\hline \multicolumn{2}{|c|}{$\begin{array}{l}\text { - Criar uma ambientação capaz de reproduzir as sensações de estar no } \\
\text { útero materno; } \\
\text { - Levar a criança a viver a experiência para além da imitação de um } \\
\text { bebê. }\end{array}$} & $\begin{array}{l}\text { - Pesquisa de músicas } \\
\text { e sons; } \\
\text { Estimular a criança } \\
\text { pelo apelo às } \\
\text { sensações } \\
\text { provocadas pela } \\
\text { ambientação criada. }\end{array}$ \\
\hline
\end{tabular}

Fonte: a autora, 2019

Registros do processo:
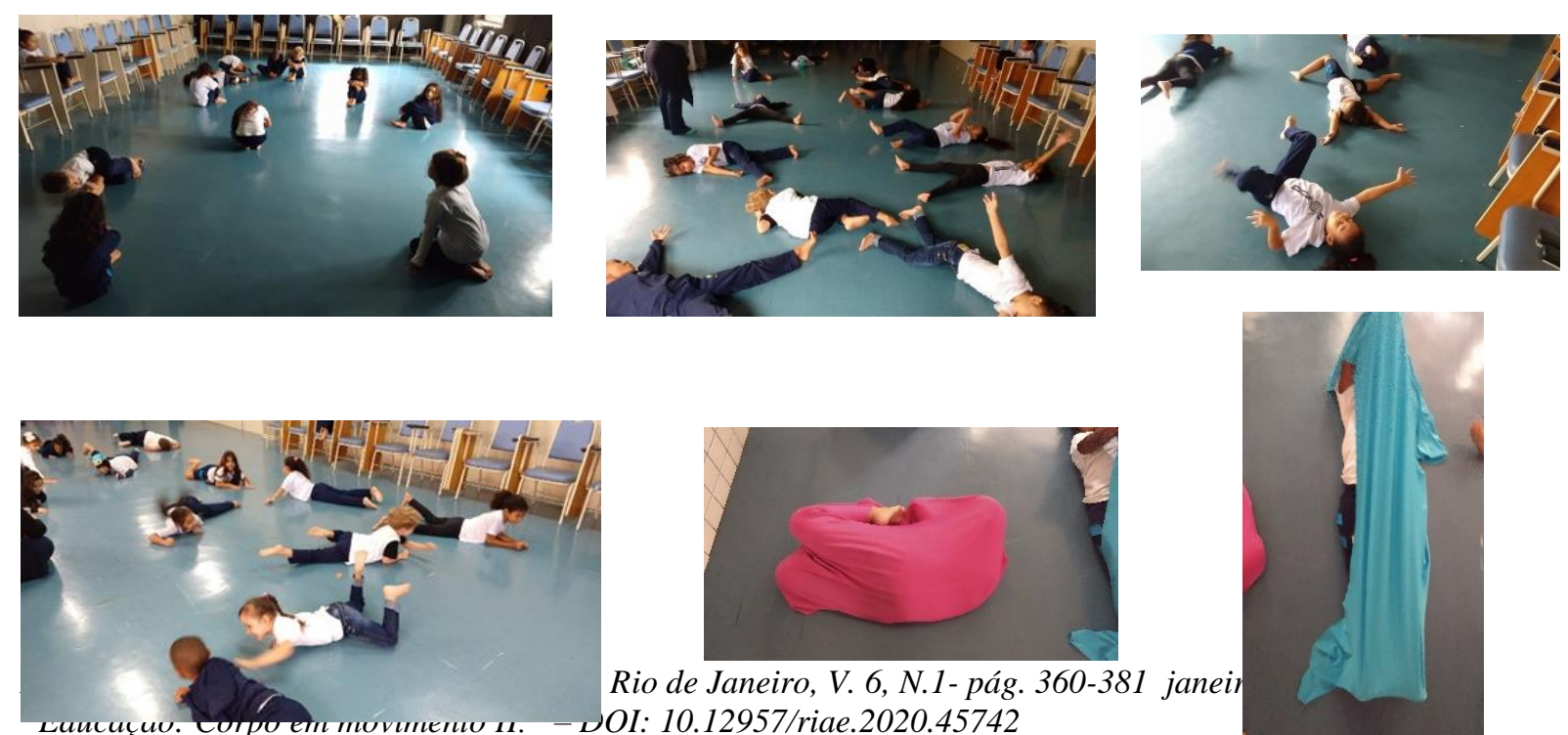

Rio de Janeiro, V. 6, N.1-pág. 360-381 janei OI: 10.12957/riae.2020.45742 


\section{Considerações finais}

Como um dos desafios a serem superados neste tipo de proposta, destaca-se a necessidade de desconstrução do modelo eurocêntrico do ensino da Dança no contexto da Educação formal, uma vez que este modelo se limita à reprodução de saberes alheios a realidade do aluno. Contudo, isso não impede que tais saberes ainda hegemônicos sejam repensados e reconstruídos com uma prática que considere a criança como sujeito ativo, abrindo-se espaço ao diálogo e aos seus questionamentos.

Pelas experiências relatadas, entende-se que mais que uma estratégia, a ludicidade é uma condição para a construção do conhecimento na Educação Infantil e implica a capacidade do educador em explorar o interesse e a atenção mobilizada pela criança para o objeto lúdico ou para o jogo, a fim de estimular suas descobertas sobre o corpo e suas relações com o mundo.

Com o desenvolvimento do tema "Corpo brinquedo", o relato evidencia que as crianças puderam compreender coletivamente que o conjunto das partes forma o corpo em sua totalidade e ainda como tais partes se articulam. Foi possível também, experimentar e descobrir as possibilidades de movimento de cada parte e da parte junto ao todo.

Para manipular o boneco e fazê-lo dançar, as crianças precisaram perceber o movimento no seu próprio corpo e, ao imitar os movimentos do boneco, estimulou-se o desenvolvimento da propriocepção, experiência fundamental para que a criança se aproprie da sua imagem corporal.

Explorando a relação do corpo com o espaço, foram abordadas noções fundamentais como a localização da parte (em cima, em baixo, na frente, atrás, ao lado), os níveis de execução do movimento no espaço pessoal, as direções e sentidos do movimento do corpo no espaço global.

Com a experiência do tema "O bebê", foi possível vislumbrar um caminho em direção ao desenvolvimento de novas propostas metodológicas para o ensino de Dança na Educação Infantil. Esse caminho busca superar o seu modelo tradicional, ou seja, aquele cujas práticas baseiam-se na aprendizagem motora por meio da imitação e na aquisição de um repertório de movimentos para se chegar ao entendimento do corpo como linguagem e da Dança como manifestação da linguagem corporal. 


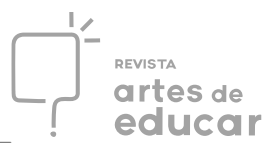

Além disso, com uma imagem da criança como ser ativo e produtor de cultura, é possível estabelecer uma relação de coprotagonismo entre criança e educador no processo de construção do conhecimento por meio da Dança.

Pudemos perceber, por meio das teorias e conceitos apresentados que, para elaborar um projeto de ensino da Dança para a Educação Infantil, é necessário que, além de transformar a sua imagem a respeito da criança na primeira infância, o Dança-Educador compreenda qual é o seu verdadeiro papel no contexto escolar.

Com a identificação de algumas das experiências essenciais para o ensino de Dança na Educação Infantil, ficou claro quais tipos de ações devem ser adotados pelo Dança-Educador e que vão diferenciá-lo do professor que atua no contexto do ensino profissionalizante, ações essas que caracterizam um papel de mediador da aprendizagem e não de um modelo a ser seguido.

Concluindo, podemos afirmar que a busca de uma "Educação Libertadora" por meio da Dança exige do Dança-Educador uma capacidade crítica sobre o seu papel social e político. Nesse sentido, é preciso que ele reflita a respeito da sua importância em questões como a legitimação dos saberes e dos modos de ensino dessa linguagem no contexto da Educação Infantil.

\section{REFERENCIAS}

ALMEIDA L.R. DE; MAHONEY A. A. (ORGS.). Afetividade e Aprendizagem Contribuições de Henri Wallon. São Paulo: Edições Loyola, 2007.

ALMEIDA, Fernanda de Souza. A Dança e a Criança de Educação Infantil: um caminho de aproximação. São Paulo, SP [s.n.] [2011?]. Não paginado.

ALMEIDA, Maria Salete Bertholazzi. Educação não formal, informal e formal do conhecimento científico nos diferentes espaços de ensino e aprendizagem. In: Produções Didático-Pedagógicas. Os desafios da escola pública paranaense na perspectiva do professor PDE. Governo do Estado do Paraná. Secretaria de Educação, 2014 (Cadernos PDE, v. II).

BALDI, Neila Cristina. Decolonialidade e Educação: entre teorias e práticas subversivas. Revista Interinstitucional Artes de Educar, Rio de Janeiro, v.3, n.3, p-293315, out/jan. 2018.

BARBOSA, C.F.; GOMES, R. F. M. A importância da brincadeira para criança de acordo com Jean Chateau. CONCOCE/CONDICE: Brasília, 2010. 


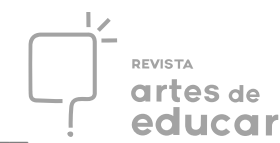

BARDIN, Laurence. Análise de conteúdo. São Paulo: Edições 70, 2016.

BEHRENS, Marilda Aparecida. Metodologia de projetos num paradigma da complexidade. Paradigma da Complexidade. Petrópolis: Vozes. 2006.

\section{BRASIL, Diretrizes Curriculares Nacionais da Educação Básica/Ministério da} Educação. Brasília: MEC, 2013.

BRASIL. Lei n 9.394, de 20 de dezembro de 1996. Estabelece as diretrizes e bases da Educação nacional. Disponível em: http://www.planalto.gov.br/ccivil_03/leis/19394.htm. Acesso em: 22/11/2019.

CAROLYN EDWARDS; LELLA GANDINI; GEORGE FORMAN. As cem linguagens da criança: a experiência de Reggio Emília em transformação. Porto Alegre: Penso, 2016. p. 237-251.

DAMÁSIO, Cláudia. A dança para crianças. In: PEREIRA, R.; SOTER, S. (orgs.) Lições de Dança 2. Rio de Janeiro: UniverCidade, 2000.

DANTAS, Heloísa. A afetividade e a construção do sujeito na psicogenética de Wallon. In: DE LA TRAILLE, Y.;OLIVEIRA, M.K.; DANTAS, H. Piaget, Vigotsky, Wallon: teorias psicogenéticas em discussão. São Paulo: Summus, 1992. p. 85-98.

ERICKSON, F. (1986). Qualitative research on teaching. In: WITTROCK, M. Handbook of research on teaching. New York: MacMillan.

GIL, ANTÔNIO CARLOS. Como elaborar projetos de pesquisa. 5. ed. São Paulo: Atlas, 2010.

GOLDEBERG, Miriam. A arte de pesquisar: como fazer pesquisa qualitativa em Ciências Sociais. Rio de Janeiro: Record,1997.

GOMES, Cleomar F. Brinco, logo existo - o papel da ludicidade na educação escolar.In GRANDO, B., S. (org.). Corpo, Educação e Cultura: Práticas Sociais e Maneiras de ser. Ijuí: Editora Unjuí, 2009. p. 111-118.

GRANDINO, P. J. Wallon e a psicogênese da pessoa na educação brasileira. In: GRATIOTALFANDEÉR, Hélène. Henri Wallon. Recife: Fundação Joaquim Nabuco, Ed. Massanga, 2010. p. 31-42. Coleção Educadores.

GUANAIS, Saryta Garrossino. Aula de mim: a linguagem corporal na Educação Infantil e o protagonismo da criança no ensino de Dança.Dissertação (Mestrado em Artes) - Universidade Federal de Minas Gerais, Programa de Pós-Graduação em Artes da Escola de Belas Artes. Belo Horizonte, 2017.

HUIZINGA, Johan. Homo Ludens: o jogo como elemento da cultura. 4. Ed. São Paulo: Ed. Perspectiva, 1999. 
LABAN, Rudolf. Dança Educativa Moderna. São Paulo: Ícone, 1990.

MALAGUZZI, Loris. História, ideias e filosofia básica. In: CAROLYN EDWARDS; LELLA GANDINI; GEORGE FORMAN. As cem linguagens da criança: a abordagem de Reggio Emília na educação da primeira infância. Porto Alegre: Penso, 2018. p. 57-98 .

PENNA, Camila. Paulo Freire no pensamento decolonial: um olhar pedagógico sobre a teoria pós-colonial latino-americana. Revista de Estudos e Pesquisa sobre as Américas, v.8, n.2, p-181-199. 2014.

RENGEL, Lenira Peral. Dicionario Laban. 2001. Dissertação (Mestrado em Artes) Universidade Federal de Campinas, Curso de Mestrado em Artes do Instituto de Artes. Campinas, 2001.

RINALDI, Carlina. A pedagogia da escuta: a perspectiva da escuta de Reggio Emília. In: SÁ, Alessandra Latalisa de. Um olhar sobre a abordagem educacional de Reggio Emilia.Paidéia, Belo Horizonte, Ano 7, n. 8, p.55-80, jan./jun.2010.

STOKOE, Patrícia; HARF, Ruth. Expressão Corporal na pré-escola. São Paulo: Summus, 1987.v.30.

WALLON, Henri. Do ato ao pensamento: ensaio de psicologia comparada. Petrópolis, RJ: Vozes, 2008.

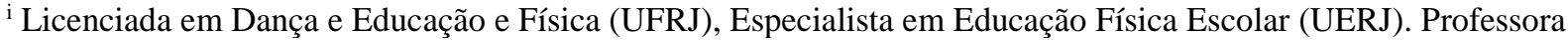
de Educação Física do Centro de Referência em Educação Infantil e Coordenadora do Projeto "Dança Criança!" (Colégio Pedro II). Mestranda do Programa de Mestrado Profissional em Práticas da Educação Básica (Colégio Pedro II). Ex-professora das Redes Municipal e Estadual de Ensino do Rio de Janeiro e da Rede Municipal de Duque de Caxias onde atuou na Educação Infantil, no Ensino Fundamental e na Educação de Jovens e Adultos. Ex-professora do CEFETQ (Ensino Técnico Integrado). Colégio Pedro II. carlavetrigo@ gmail.com Rio de Janeiro, Brasil. https://orcid.org/0000-0002-9020-9021
}

${ }^{2}$ Segundo Behrens; Oliari (2007), o paradigma emergente é fruto das transformações culturais da sociedade do nosso tempo, que, por sua vez, gera implicações no campo da Educação refletidas por meio de uma prática docente na qual o aluno precisa ter voz.

\footnotetext{
${ }^{3}$ Segundo Almeida (2011, p. 11), "a educação formal ocorre em espaços sistematizados de educação, inserida no planejamento político-pedagógico de uma escola e regulamentada por Lei Federal". Nesse sentido, considerase o "Dança Criança!" um projeto para a Educação Formal, já que este dialoga com o projeto político-pedagógico da instituição e que, com o sancionamento da Lei no 13.278/2016, a Dança tornou-se uma das áreas independentes da Arte.
}

${ }^{4}$ Baldi cita Boaventura de Sousa Santos (2002), explicando que os saberes hegemônicos são aqueles que, ao longo dos séculos, se constituem na Educação, o que o autor chama de "monocultura do saber".

${ }^{5}$ Segundo Santos (2002), tudo o que o cânone da ciência moderna não legitima ou reconhece é declarado inexistente, constituindo-se como um dos mecanismos de dominação capitalista. Desta hegemonia europeia do saber, deriva a perspectiva colonialista de Educação. 
${ }^{6}$ De acordo com Laban (1990 apud RENGEL, 2001, p.47), a Dança Livre "é a dança que não é ilustrada pela música e nem por uma estória. Origina-se do ritmo interno do movimento corporal que encontra sua realização nos componentes espaciais e dinâmicos”.

${ }^{7}$ O "impulso de mover-se" a que Laban se refere seria a saída natural de uma tensão interna, que para ele é a própria Dança, já que seu único propósito é o desejo instintivo da criança de desenvolver seus esforços. Porém, chama a atenção para o fato de que esse impulso é despertado nas crianças "numa idade em que já é habitual o uso controlado de um número limitado de articulações” (LABAN, 1990, p. 24).

${ }^{8}$ De acordo com Gomes (2009), o Homem pré-histórico era lúdico por natureza. Quando descobre a importância do trabalho, representada pela invenção da ferramenta, o "homo ludens" é "devorado" pelo "homo faber".

9 Este "mundo" a que nos referimos vai além da realidade na qual a criança está inserta (e que deve ser considerada). Ele diz respeito, também, às relações do corpo com certos conceitos abstratos como o peso, o espaço e o tempo, que precisam ser apropriados pela criança e que, como veremos mais adiante, ganham concretude na Dança.

${ }^{10}$ A "conduta lúdica", conceito definido por Chateau, é entendida como aquela situação em que, independentemente da idade, se escapa de tudo que nos engessa, permitindo-nos ingressar em um ambiente de fantasia (1987 apud BARBOSA; GOMES, 2010).

${ }^{11}$ Centro de Referência em Educação Infantil (Colégio Pedro II/Campi Realengo).

${ }^{12}$ Segundo Penna (2014), o "mito do eurocentrismo" foi uma estratégia de dominação e exploração por meio do qual os colonizados introjetaram uma visão de si como atrasados e inferiores, passando a ter como ideal civilizatório a cultura europeia.

${ }^{13}$ Rinaldi (2016) explica que, a "escuta interna" acontece quando a criança, para comunicar suas imagens mentais aos outros, também representa a si mesma.

${ }^{14}$ Termo usado por Fraser; Gestwich (2000 apud MALAGUZZI, 2016) para elencar as dimensões englobadas no papel do professor.

${ }^{15}$ Rinaldi (2016) nos lembra que o termo avaliação deriva de valor. Portanto, avaliar é o mesmo que atribuir valor.

${ }^{16}$ Projeto de ensino realizado desde 2017 com alunos da Educação Infantil do Colégio Pedro II que atende aos grupamentos 4 e 5 (faixa etária entre 4 e 6 anos), em encontros semanais, com duração de 1 hora e 30 minutos.

${ }^{17}$ De acordo com Rengel (2001), a "Corêutica" é o estudo da organização espacial dos movimentos desenvolvido por Laban, que trata do espaço no corpo (estabelecendo lugares no espaço com o corpo) e do corpo no espaço (quando o espaço é a referência direcional do corpo). 